\title{
Darb-e Imam Tessellations: A Mistake of 250 Years
}

\author{
Luc Lauwers ${ }^{1}$ (D)
}

Published online: 23 June 2018

(C) Kim Williams Books, Turin 2018

\begin{abstract}
A particular mosaic at the Darb-e Imam mausoleum in Isfahan has caused some controversy 10 years ago when it was claimed to exhibit quasi-periodic properties and that it was 500 years old. The technical part of this claim has been disputed (and refuted) by several authors. The date, 1453, also a key part of the press coverage that medieval Islamic artisans did advanced mathematics 500 years before the West, has not been challenged. We argue that the panel in question dates from the end of the Safavid period (1715-1717). Techniques developed during the Safavid period seem to be wrongly attributed to the fifteenth century.
\end{abstract}

Keywords Islamic pattern · Isfahan · Timurids · Safavids · Eighteenth century

\section{Introduction}

This note discusses the dating of two tessellations in the Imamzadeh Darb-e Imam in the northern part of Isfahan. A contribution by Lu and Steinhardt (2007) states that one of these tessellations has the potential to extend to a perfect quasi-crystalline pattern, also known as a Penrose pattern. This contribution generated a lot of publicity and raised interest in Islamic art with the general public. ${ }^{1}$

This claim by Lu and Steinhardt, however, has been questioned by different scholars. Makovicky (2007), for example, argues that the pattern is periodic

\footnotetext{
1 See, e.g., The pattern on the Darb-e Imam shrine, built in 1453, is almost identical to Penrose tilings, discovered in 1973 (Nature, Feb 2007), Islamic artisans constructed exotic nonrepeating pattern 500 years before mathematicians (Scientific American, Feb 2007), and Islamic artists were 500 years ahead of Western scientists (The Independent, London Feb 2007).
}

Luc Lauwers

Luc.Lauwers@kuleuven.be

1 Department of Economics, KU Leuven, Naamsestraat 69, 3000 Leuven, Belgium 
(augmented with derivatives of the Maragha pattern). He concludes (Makovicky 2007: 1383):

... we believe that the artisans were satisfied by creating a large fundamental domain without being concerned with a mathematical notion of infinitely expandable quasiperiodic patterns.

Also, contributions by Cromwell (2016) and Castéra (2016) do not find evidence that Islamic artists were aware of any process for producing quasi-periodic designs. ${ }^{2}$ These publications, however, date the respective tessellations to 1453 during the Timurid era.

Golombek and Wilber (1988) and Varjavand (1994), in contrast, indicate that these tessellations date from 1715-1717 during the reign of Shah Soltan Hosayn (r. 1694-1722). In this note, we recall the historical context and we connect these Darb-e Imam tessellations to tessellations in the west iwan of the Friday Mosque (1700) and in the Madrasa Chahar Bagh (1704-1710). This connection, therefore, provides further evidence to position all these tessellations in the early eighteenth century. As such, we will conclude that the date, 1453, which formed a key part of the press coverage that medieval Islamic artisans did advanced mathematics 500 years before the West, is incorrect. Furthermore, techniques developed during the Safavid period seem to be wrongly attributed to the fifteenth century.

\section{The Imamzadeh Darb-e Imam and its Historical Context}

The word imamzadeh is used to refer to the shrine where a descendant of an Imam (a male descendant of Muhammad through his daughter Fatima) is buried and to the actual descendant as well. Shi'a pilgrims may forge alliances with imamzadeh through vows, offering some form of sacrifice in exchange for the Imamzadeh's assistance. Actually, the act of appealing to imamzadeh is already empowering and offers consolation. ${ }^{3}$

The Imamzadeh Darb-e Imam in Isfahan is a large shrine complex, centered on a burial chamber identified by a Safavid inscription as that of Ebrahim Batha and Zayn-al-'Abedin. Golombek and Wilber (1988) and Varjavand (1994) describe the complex as an aggregate of several periods. The oldest structure was built in 1453 during the Timurid era (ca. 1370-1507) and consists of an entrance portal, a square vestibule, and a mausoleum. Figure 1 (Golombek and Wilber 1988, Fig. 126) shows this initial construction in full black. With respect to the decorative treatment, the mosaic faience is considered outstanding in quality and originality, comparable to the contemporary mosaics at the Blue Mosque in Tabriz. ${ }^{4}$

\footnotetext{
${ }^{2}$ Makovicky $(2015,2016,2017)$ further elaborates the issue and concludes, similar to Cromwell (2016), that the tympanum pattern is constructed by filling compartments and not by subdivisions of the total pattern. Also Bonner (2017: 141 and 501) rejects the claim that the Darb-e Imam tessellation is not embedded in a periodic framework. As a matter of fact, the notions of periodicity and aperiodicity do not occur in Medieval Islamic literature (Hogendijk 2011: 255).

3 See, e.g., Glazebrook and Jalal Abbasi-Shavazi (2007).

4 Necipoğlu (1992) and Abdullahi and Embi (2015) discuss the Timurid decorations of the Darb-e Imam.
} 


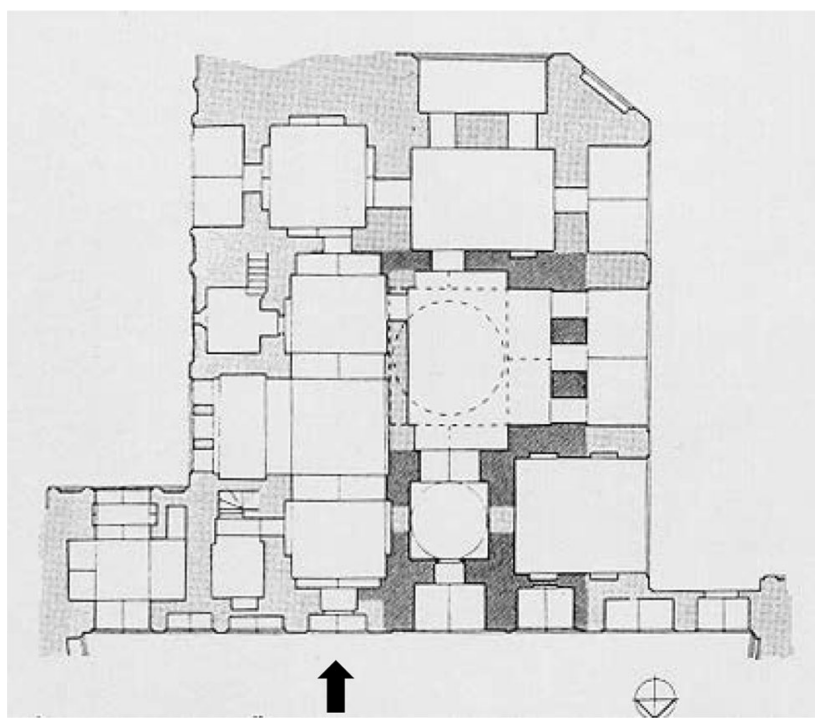

Fig. 1 Darb-e Imam, plan of the complex (Golombek and Wilber 1988 http://www.iranicaonline.org/ articles/darb-e-emam). The arrow points towards the present entrance

In the centuries that followed, a number of tombs were added to the vestibule. Eventually their number forced the original entrance to close: during the reign of Shah Solayman (r. 1666-94) the original door was replaced by a window, and henceforth, the shrine had to be entered directly from the south.

During 1715-1717, at the end of the Safavid dynasty and under the reign of Shah Soltan Hosayn (r. 1694-1722), the complex was extended. Figure 1 shows how a new portal was attached to the east side of the original structure. Furthermore, three courts were added on the north, east, and west of the shrine. The two adjacent portals of the Darb-e Imam represent a unique iuxta position of two different eras. According to Jackson and Lockhart (1986: 765) the composition of the original 1453-portal adumbrates that of the attached Safavid portal. Figure 2 shows the tympanum above the present entrance. ${ }^{5}$ The much-debated spandrel (Lu and Steinhardt 2007, Fig. 3) is located at the northern court of the Imamzadeh.

An Arabic inscription, directly above the present entrance and below the tympanum, indicates the date of this particular extension. The bottom-line (Fig. 2) shows 1129 (AH) which corresponds to $1717 \mathrm{CE}$. This inscription and the descriptions by Golombek and Wilber (1988) and Varjavand (1994) have been overlooked in the recent literature on Islamic patterns. One further remark ${ }^{6}$ should be included here: the inscription uses the term Ta mìr (تعمير) which means building, construction, erection, reconstruction, repair, refurbishing (Wehr and Cowan 1976:

\footnotetext{
5 For alternative pictures, see, among others, Wade (2018, IRA 0908) and Makovicky (2016, Fig. 7.5).

6 I thank the referee for this observation. I thank Professor Amr Ryad for his help in the transliteration of the 1717-inscription.
} 


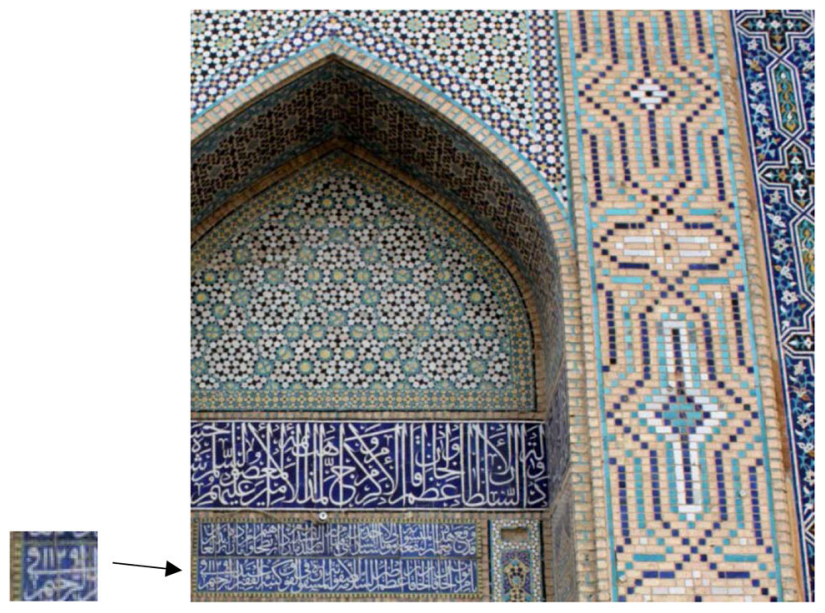

Fig. 2 Darb-e Imam, tympanum. The inscription 1 r 9 refers to $1129 \mathrm{AH}$ or $1717 \mathrm{CE}$. The triangle along the right boundary of the picture shows a small part of the original 1453-portal (floral motifs). Photo courtesy of Marina Alin. https://marinaalin.wordpress.com/2013/09/18/weaving-in-clay/darb-e-imamshrine-isfahan-iran/

644). ${ }^{7}$ The use of this term, thus, leaves open whether or not the tympanum panel is older and was left in place during the (re)constructions. On the other hand, the detailed descriptions by Golombek and Wilber (1988: 384-386) insist on an early Timurid building that has been modified at the end of the Safavid period. Although some parts of the core structure may have been destroyed during these renovations, the present entrance does not belong to the original Timurid structure. The next section provides further arguments.

Bonner (2003) positions the Safavid tessellation in 1453 on the basis of Hutt and Harrow (1979). ${ }^{8}$ This 177-page book includes 148 plates and an introductory chapter of 13 pages summarising the history of Iran from 1314 until 1924. As the explanations are rather modest, Hutt and Harrow (1979) do not seem to be the best source for historical research. The classic book on Timurid architecture by Golombek and Wilber (1988) and the Encyclopædia Iranica are not included in the bibliography of Bonner (2003).

This 1453-dating of the Safavid tessellations has been persistent: see, e.g., Lu and Steinhardt (2007), Zheludev and Ozbay (2007), Saltzman (2008), Dewar (2009), Ferrero et al. (2009), Juhel (2012), Todesco (2012), Al Ajlouni (2012, 2013), Au-Yang and Perk (2013), Tennant (2014), Topper (2014), Ebrahimi and Aliabadi (2015), Williams and Ostwald (2015), Aube (2016), Bier (2011, 2012, 2017),

\footnotetext{
7 The term Ta'mīr finds its roots in the verb 'amara which means to build, construct, rebuild, restore, ... (Wehr and Cowan 1976: 643). The inscription is compatible with "the addition of new parts" to the existing structure.

${ }^{8}$ Footnote 13 in Bonner (2003: 5) refers to Hutt and Harrow (1979: 61-65).
} 
Cromwell (2015, 2016), Castéra (2016), Makovicky (2007, 2016), Bonner (2017), Lissek et al. (2017), Pautze (2017), Wichmann and Wade (2017). ${ }^{9}$

In addition, it seems that Bonner's (2003) claim that four designs (his Figs. 4, 5, 7, and 8) are the work of Sayyid Mahmud-i Naqqash is not fully supported by Hutt and Harrow. ${ }^{10}$ Three patterns (Figs. 5, 7, and 8 in Bonner) are in relief and are clearly based on the same idea. Bonner labels these designs as type $B$. The design in his Fig. 4 (our Fig. 2, above) is essentially different, making it not a type $B$ design. Let us now look at Hutt and Harrow's comments. Figures 5 and 7 in Bonner are borrowed from Plates 36 and 41 in Hutt and Harrow, and show designs from Varzaneh (dated 1443) and Isfahan (dated 1475). The explanation of Hutt and Harrow on the 1475-design reads: "It is particularly interesting because of the continued use of the raised mosaic pattern, seen earlier at Varzana and the Darb-i Imam."And, with respect to the Darb-e Imam, Hutt and Harrow (1979, Plate 40) write: "Many of the designs used relate to the work of Sayyid Mahmud, including the raised pattern motif." 11

Furthermore, Hutt and Harrow (1979, Plate 40) mention that the Darb-e Imam was extended in the late Safavid era. In conclusion, the statements of Hutt and Harrow do support the similarities between Figs. 5, 7, and 8 in Bonner. On the other hand, Hutt and Harrow (1979) do not provide any support to assign the design shown in Fig. 4 in Bonner (our Fig. 2, above) to Sayyid Mahmud or to $1453 .{ }^{12}$

The dating of tessellations can often be difficult: a facade that has been restored may have a completely new decorative scheme in the latest fashion or, even if it is based on the earlier design, it may be modified or updated. However, recall that according to Golombek and Wilber (1988) and Varjavand (1994), the present entrance of the Darb-e Imam is part of the 1717 extension on the east side of the original structure. Undoubtedly, a primary source, such as the inscription $1129 \mathrm{AH}$, should be included in the discussions while dating a tessellation.

\footnotetext{
9 See Cromwell (2016) for additional references. As a matter of fact, when searching (April 2018) through the literature on Islamic geometric patterns, I was unable to find a publication that assigns the Darb-e Imam tympanum to the Safavid era.

10 This claim has been repeated in later publications (e.g., Saltzman 2008, Cromwell 2016, Bonner 2017).

11 The design shown in Fig. 8 in Bonner (2003) fits this description.

12 Also the works by Blunt, Godard, and Pope — listed in the bibliography of Hutt and Harrow (1979) — do not provide any support to the claim of Bonner. The description of the Darb-e Imam by Godard (1962: 386) is completely in line with Golombek and Wilber (1988) and Varjavand (1994). Blunt (1966: 19, 48) and Pope (1965: 198) connect the name of Sayyid Mahmud to the hall for winter prayers in the Isfahan Friday Mosque (1447). Blunt (1966: 48) gives a brief description of the 1453-part of the Darb-e Imam. Finally, Pope (1965: 203, lines 1-3) spends half a sentence on the Darb-e Imam:

"...; while the portal of the Darb-i-Imam, also in Isfahan, a memorial to two Imams built in 1453, is one of the finest examples of decorated architecture in Persia."

This short statement by Pope (1965) is not sufficient to position the whole of the Darb-e Imam in 1453.
} 


\section{Contemporaneous Tessellations}

Cromwell (2016) surveys 40 examples of two-level patterns in Islamic geometric ornament from Iran and Central Asia, and brings four tessellations together: the tympanum and the particular spandrel of the Darb-e Imam, the west iwan of the Isfahan Friday Mosque, and a keyhole subset of a rectangular panel at the Chahar Bagh Madrasa in Isfahan. The tessellations in this Isfahan quartet appear to have the same characteristics: two-level design, inlaid line, $M\{10 / 3\}$, standard triad, and scale $4+2 \sqrt{5}$ (Cromwell 2016, Catalogue nrs 3, 4, 10, and 17). Furthermore, in this catalogue, only these four tessellations share these particular characteristics.

These four tessellations are within walking distance from each other. The Friday Mosque and the Darb-e Imam are located in the northern part of central Isfahan. The Chahar Bagh Madrasa is just south of the main square developed by Shah Abbas (r. 1588-1629 CE) when he moved his capital to Isfahan. Bonner (2016: 146) recognises the similarities between the Darb-e Imam tympanum and the west iwan of the Isfahan Friday Mosque, and suggests and motivates that these designs were created by one single artist or at least by artists working within the same atelier. Next, Cromwell (2015: 39) observes similarities between the Darb-e Imam spandrel and a tessellation at the Chahar Bagh Madrasa, on the basis that they both show a particular deceptive construction.

Furthermore, the use of yellow that invades the colour scheme in these tessellations is a characteristic of late Safavid ornaments (e.g., Jackson and Lawrence 1986: 810). And although the Safavid designers never lost sight of their Timurid architectural heritage, the floral motifs (present in the 1453-entrance of the Darb-e Imam) are less present in the late Safavid tessellations (e.g., Abdullahi and Embi 2015).

Finally, the four tessellations show a two-level design. There are different ways to display the large scale pattern. One method shows the large scale-pattern by means of a thin line inlaid along the edges of the large-scale pattern. This method, however, might deform the small ten-pointed stars positioned at the crossing of two lines (making an acute angle). These kinds of small deformations are visible at the Darb-e Imam tympanum and at the west iwan of the Friday Mosque (2018, IRA 0908 and IRA 0601). In addition, when the inlaid lines become thicker, the regularity of the large pentagonal shapes might be lost (e.g. the spandrel of the Darb-e Imam). ${ }^{13}$ The catalogue of Cromwell (2016) lists four monuments that use this method of inlaid lines: the west iwan of the Friday Mosque, the Chahar Bagh Madrasa, the Darb-e Imam, and the nineteenth century Seyyed Mosque in Isfahan.

In sum, the four two-level designs at the west iwan of the Friday Mosque, the Chahar Bagh Madrasa, and at the Darb-e Imam share the same characteristics. These links support the contemporaneity of these tessellations.

Let us now look at the dating of these tessellations. The Chahar Bagh Madrasa dates from 1704-1710 within the reign of Shah Soltan Hosayn (Haneda and Matthee 2006; Babaie and Haug 2007). Next, although the construction of the west iwan of

\footnotetext{
13 Cromwell (2015: 39) observes these kinds of deceptive constructions at the Darb-e Imam spandrel and at the Chahar Bagh Madrasa. See also Chapter 15 in Wichmann and Wade (2017).
} 
the Friday Mosque began in the early twelfth century, the faience decorations on the outer wall, the interior, and the vault date from the early eighteenth century (Honarfar 1976; Chorbachi 1989; Arab 1996). An Arabic inscription (Wade 2018, IRA 0530) shows 1112 (AH). This corresponds to $1700 \mathrm{CE}$ and falls again within the reign of Shah Soltan Hosayn (r. 1694-1722). ${ }^{14}$

Dating the Isfahan quartet at the late Safavid era does not entail that the patterns originate from this period. Artisans were equipped with pattern books such as, for example, the Topkap1 Scroll and had access to previous patterns. ${ }^{15}$ The statement, however, entails that the technique of inlaid lines might be developed during the late Safavid era. Indeed, within the catalogue of Cromwell (which includes, e.g., the early Varzaneh design (CE 1443)), the tessellations in the Isfahan quartet are the earliest two-leveled designs with inlaid lines.

\section{Conclusion}

Although extensively documented, the history of the Imamzade Darb-e Imam has been overlooked in the literature on the mathematics behind Islamic geometric ornament. Given the evidence cited above, the following timeline emerges and is supported by primary sources and by similarities in style: Friday Mosque, decoration of the west iwan (1700), Chahar Bagh Madrasa (1704-1710), and the Darb-e Imam extension (1715-1717). ${ }^{16}$ The date, 1453, which formed a key part of the press coverage on the Darb-e Imam tessellations, is definitely wrong. The above timeline entails that the technique of two-level patterns with inlaid lines is developed during the late Safavid era.

Acknowledgements The author wishes to thank the referee and the editor for detailed and insightful comments.

\section{References}

Abdullahi, Yahya and Mohamed Rashid Embi. 2015. Evolution of Abstract Vegetal Ornaments in Islamic Architecture. International Journal of Architectural Research 9: 31-49.

Al Ajlouni, Rima. 2012. The Global Long-Range Order of Quasi-periodic Patterns in Islamic Architecture. Acta Crystallographica A-Foundation and Advances 68: 235-243.

Al Ajlouni, Rima. 2013. Octagon-Based Quasicrystalline Formations in Islamic Architecture. In: Schmid S., Withers R., Lifshitz R. (eds) Aperiodic Crystals. Dordrecht: Springer.

\footnotetext{
${ }^{14}$ Lu and Steinhardt (2007, Supplementary figure S7B) and Bonner (2017) date these decorations at the late fifteenth century (Timurid era). The Timurid parts of this mosque, however, are listed and described in Golombek and Wilber (1988: 378-381): the portal at the north, the winter masjid, the south iwan, and the iwan of Umar.

15 As the Topkap1 Scroll is probably compiled in the late 15th or 16th somewhere in western or central Iran (Necipoğlu 1995: 37-38), the timeline proposed in this note suggests that the scroll predates the Isfahan quartet.

16 As already mentioned, the dating of tessellations can be difficult. Although my arguments, I believe, convincingly point to a late Safavid dating, they do not constitute a rigorous mathematical proof. In view of this, I thank the referee and the editor for the opportunity to publish this note and to expose my arguments to criticism.
} 
Arab, Gholam Hosein. 1996. Isfahan. Teheran: Bazaarcheh Ketab.

Aube, Sandra. 2016. The Uzun Hasan Mosque in Tabriz: New Perspectives on a Tabrizi Ceramic Tile Workshop. Muqarnas 33: 33-62.

Au-Yang, Helen and Jacques H.H. Perk. 2013. Quasicrystals-The impact of N.G. de Bruijn. Indagationes Mathematicae 24: 996-1017.

Babaie, Sussan and Robert Haug. 2007. Isfahan, Monuments, Madrasas. In: Encyclopadia Iranica, Vol. XIV, Fasc. 1: 33-35 (updated 2012). New York City: Columbia University.

Bier, Carol. 2011. Taking Sides, But Who's Counting? The Decagonal Tomb Tower at Maragha. Proceedings of Bridges: Mathematics, Music, Art, Architecture, Culture.

Bier, Carol. 2012. The Decagonal Tomb Tower at Maragha and Its Architectural Context: Lines of Mathematical Thought. Nexus Network Journal 14: 251-273.

Bier, Carol. 2017. Alloys and Architecture: Periodic and Quasiperiodic Patterns in Sinan's Selimiye in Edirne. In: Manar Ç., Horowitz M.T., Gilbert A.S. (eds.) Overturning Certainties in Near Eastern Archaeology, A Festschrift in Honor of K. Aslihan Yener. Leiden: Brill.

Blunt, Wilfrid. 1966. Isfahan, Pearl of Persia. London: Elek Books Limited.

Bonner, Jay F. 2003. Three Traditions of Self-similarity in Fourteenth and Fifteenth Century Islamic Geometric Ornament. In: Meeting Alhambra: ISAMA Bridges, Conference Proceedings, 1-12, University of Granada. http://archive.bridgesmathart.org/2003/bridges2003-1.html.

Bonner, Jay F. 2017. Islamic Geometric Patterns, Their Historical Development and Traditional Methods of Construction. New York: Springer-Verlag.

Castéra, Jean-Marc. 2016. Persian Variations. Nexus Network Journal 18: 223-274.

Chorbachi, Wasma'a Khalid. 1989. In the Tower of Babel: Beyond Symmetry in Islamic Design. Computers \& Mathematics with Applications 17: 751-789.

Cromwell, Peter R. 2015. Cognitive bias and claims of quasi-periodicity in traditional Islamic patterns. Mathematical Intelligencer 37: 30-44.

Cromwell, Peter R. 2016. Modularity and Hierarchy in Persian Geometric Ornament. Nexus Network Journal 18: 7-54.

Dewar, Robert Earl. 2009. Islamic Girih Tiles in Their Own Right as a History Lesson and Design Exercise in the Clasroom. Symmetry: Culture and Science 20: 201-2016.

Ebrahimi, Ahad Nejad and Morteza Aliabadi. 2015. The Role of Mathematics and Geometry in Formation of Persian Architecture. Asian Culture and History 7: 220-239.

Ferrero, Giovanni; Cotti, Celestina; Rossi, Michela, and Cecilia Tedeschi. 2009. Geometries of Imaginary Space: Architectural Developments of the Concepts of M.C. Escher and Buckminster Fuller. Nexus Network Journal 11: 305-316.

Glazebrook, Diana and Mohammad Jalal Abbasi-Shavazi. 2007. Being Neighbors to Imam Reza: Pilgrimage Practices and Return Intentions of Hazara Afghans Living in Mashhad, Iran. Iranian Studies 40: 187-201.

Godard, Andre. 1962. L'art de l'Iran. Paris: C.B. Arthaud.

Golombek, Lisa and Donald Wilber. 1988. The Timurid Architecture of Iran and Turan. Princeton: Princeton University Press.

Haneda, Masashi and Rudi Matthee. 2006. Isfahan vii, Safavid Period. In: Encyclopæedia Iranica, Vol. XIII, Fasc. 6: 650-657 (updated 2012). New York City: Columbia University.

Hogendijk, Jan P. 2011. Middeleeuwse Islamitische Geometrische Ornamentiek. Nieuw Archief voor Wiskunde, 12: 253-258.

Honarfar, Lotfollah. 1976. Historical Monuments of Isfahan. Teheran: Ziba Press, Eighth Edition.

Hutt, Antony and Leonard Harrow. 1979. Iran 2. London: Scorpion Publication Ltd.

Jackson, Peter and Lawrence Lockhart. 1986. The Cambridge History of Iran, Volume 6: The Timurid and Safavid Periods. Cambridge: Cambridge University Press.

Juhel, Alain. 2012. Touring Persia with a Guide Named... Hermann Weyl. Nexus Network Journal 14: 203-226.

Lissek, Thomas; Adams, Michelle; Adelman, John; et al. 2017. Building Bridges through Science. Neuron 96: 730-735.

Lu, Peter J. and Paul J. Steinhardt. 2007. Decagonal and Quasi-crystalline Tilings in Medieval Islamic Architecture. Science, 315 no. 5815: 1106-1110.

Makovicky, Emil. 2007. Comment on "Decagonal and Quasi-Crystalline Tilings in Medieval Islamic Architecture". Science, 318 no. 5855: 1383.

Makovicky, Emil. 2015. In the Footsteps of Maragha: Ornamental Panels in the Madrasas and Mosques of Esfahan, Konya, Agra, Sivas and Yazd. Symmetry: Culture and Science, 26: 421-441. 
Makovicky, Emil. 2016. Symmetry Through the Eyes of the Old Masters. Berlin/Boston: Walter De Gruyter.

Mackoviky, Emil. 2017. On the Kond Style of Islamic Tiling: a Study in Practical Islamic Geometry. Rendiconti Lincei, 28: 35-51.

Necipoğlu, Gülrü. 1992. Geometric Design in Timurid/Turkmen Architectural Practice: Thoughts on a Recently Discovered Scroll and Its Late Gothic Parallels. In: Lisa Golombek and Maria Subtelny (eds) Timurid Art and Culture: Iran and Central Asia in the Fifteenth Century. Leiden: Brill.

Necipoğlu, Gülrü. 1995. The Topkapı Scroll-Geometry and Ornament in Islamic Architecture. Santa Monica, CA: The Getty Center for the History of Art and the Humanities.

Pautze, Stefan. 2017. Cyclotomic Aperiodic Substitution Tilings. Symmetry 9(2), 19.

Pope, Arthur Upham. 1965. Persian Architecture. New York: George Braziller.

Saltzman, Peter. 2008. Quasi-Periodicity in Islamic Geometric Design. In: Williams, Kim (ed.) Nexus VII: Architecture and Mathematics. Turin: Kim Williams Books.

Sarhangi, Reza. 2016. Persian Architectural Elements and Mosaic Designs, both Traditional and Modern. Nexus Network Journal 18: 1-5.

Tennant, Raymond. 2014. Dissection Methods for Aperiodic Tilings: From Medieval Islamic Architecture to Quasicrystals. Conference of the International Journal of Arts and Sciences, 07 (03): 343-348.

Todesco, Gian Marco. 2012. Aperiodic Tiling. In: Emmer M. (ed.) Imagine Math. Milano: Springer.

Topper, David R. 2014. Idolatry and Infinity: Of Art, Math, and God. Brown Walker Press.

Williams, Kim and Michael J. Ostwald. 2015. Architecture and Mathematics from Antiquity to the Future (Vol I, Antiquity to the $1500 \mathrm{~s}$ ). London: Springer.

Varjavand, Parviz. 1994. Darb-e Emam. In: Encyclopcedia Iranica, Vol. VII, Fasc. 1: 11-13 (updated 2011). New York City: Columbia University.

Wade, David. 2018. Pattern in Islamic Art: The Wade Photo-Archive. https://patterninislamicart.com/

Wehr, Hans and Milton Cowan. 1976. Arabic-English Dictionary. New York: Spoken Language Services Inc.

Wichmann, Brian and David Wade. 2017. Islamic Design: A Mathematical Approach. Torino: Kim Williams Books.

Zheludev, Nikolay and Ekmel Ozbay. 2007. The Magical Land Between the Kingdoms of Nano and Meta. Journal of Optics A: Pure and Applied Optics, 9(9).

Luc Lauwers is professor at the Economics Department of the KU Leuven. He obtained a $\mathrm{PhD}$ in mathematics (1989) and in economics (1995) from the KU Leuven. He has a strong interest in the history of Egypt and Iran. 